\title{
Отголоски советского пуризма в постсоветском метадискурсе о языке
}

\author{
NAM HYE HYUN \\ Yonsei University 50, Yonsei-ro, Seodaemun-gu, Seoul, 120-749 Republic of Korea \\ E-mail: zean01@mail.ru
}

(Received: 24 February 2015; accepted: 12 May 2015)

\begin{abstract}
Significant social and political shifts cause basic changes in a language culture such as the abolition of old models of writing, speaking, and the establishment of a new model of language usage, which leads to the emergence of puristic reaction to language processes. This paper examines various manifestations of purism in the metadiscourse on modern Russian language and analyzes how they overlap with the purism in the Soviet language policy.
\end{abstract}

Keywords: metadiscourse, purism, language policy, language culture, standard language

\section{1. Введение}

Как известно, серьезные общественные перемены сопровождаются соответствующими инновациями в языковой культуре, т. е. изменениями в практике пользования языком и стилях речи. По мнению М. Горхэма, крупные социальные, политические сдвиги вызывают базисные изменения в языковой культуре, т. е. упразднение старых моделей письма, говорения и установление нового порядка, что, в свою очередь, приводит к возникновению пуристической реакции на языковые процессы (GoRHAM 2006: 19).

Языковой пуризм - это преувеличенное стремление к чистоте литературного языка, к освобождению его от всяких посторонних элементов, таких как просторечные и диалектные слова, но, прежде всего, заимствованные. Однако ни один язык не способен к существованию в замкнутом пространстве, и языковые контакты выступают как один из основных факторов развития языка. Поэтому чистота языка в таком понимании является весьма искусственным состоянием. В то же время, она как концепция обладает огромной идеологической мощью в сочетании с концептами «нация», «народ», «Государство». Ведь неслучайно пуризм приобретает особую силу в эпохи подъема национализма, отражаясь в нормализаторской деятельности, культивации языка и в политике по отношению к литературному языку. Исторически борьба за чистоту языка была связана с национализмом, расовой дискриминацией и шовинизмом (NAм 2015).

Тезис М. Горхэма о проявлении пуризма в отношениях к языку после резких изменений в языковой культуре находит подтверждение в условиях современной русской языковой ситуации. Исторические события, происхо- 
дившие в России в конце XX и начале XXI веков, не могли не оказать влияния на развитие русского языка. Распад СССР и крушение тоталитарной системы внесли значительные изменения в условия функционирования языка. Люди начали выстраивать общение, нарочно отклоняясь от прежней нормы, и в литературный язык широко вторгались субстандартные единицы, что было характерно также для послереволюционного периода. Следовательно, лексическая система быстро и наглядно изменялась, вбирая в себя много заимствований, неологизмов, происходили изменения в стилистических соотношениях словесных единиц, в частности, нейтрализация диалектизмов и просторечия. В первые послеперестроечные годы такие языковые сдвиги оценивались положительно как символ завоеванной свободы.

Однако по мере того, как усиливалось проникновение субстандартных единиц в общее употребление языка, выдвигались мнения, предостерегающие о порче языка. Можно сказать, что на протяжении нескольких последних лет русский язык был одной из излюбленных тем обсуждения широкой общественности. Относительно изменений в отношениях к языковым нормам В. С. Елистратов отметил два периода: период разрушения норм и период кристаллизации структуры. По его мнению, период конца 80-х гг. и начала и середины 90-х гг. - это период массового «разнормирования» языкового сознания, поскольку норма у многих ассоциировалась с принуждением, цензурой, идеологизированностью и т. п. В этот период люди стремились к игре с периферией лексических значений, к разрушению всех устойчивых структур. К этому относится и пародийное, игровое употребление советизмов. ${ }^{1}$ С конца же 90-х гг. наблюдается обратная тенденция: начало возвращения к авторитету нормы, к ядру значений. Данный феномен В. С. Елистратов обозначает как «кристаллизацию» структур. ${ }^{2}$ В этом новом отношении к языку зарубежные исследователи часто усматривают отголоски пуризма (GoRHAм 2000, Gorham 2006, Ryazanova-Clarke 2006).

В настоящей статье рассмотрим различные проявления пуризма в дискурсе о современном русском языке и попытаемся показать, как они перекликаются с пуризмом в советской языковой политике. По мнению Х. Шиффмана, языковая политика - это не просто текст или положения юридического документа, это своего рода система убеждений, коллекция идей, решений и, наконец, совокупность отношений к языку (SCHIFFMAN 1996: 59).

Итак, далее, во втором разделе рассматривается явление пуризма в советской языковой политике и его пропаганда посредством прессы, так как в советское время языковые вопросы обсуждались главным образом не в академических кругах, а в прессе. Третий раздел посвящается дискуссии о языке в постсоветское время. При этом, вслед за Л. Рязановой-Кларк, мы делим метадискурс о языке (metalinguistic discourse) на два субдискурса: государственный дискурс (state discourse), включающий в себя комментарии политиков и

\footnotetext{
${ }^{1}$ О ностальгическом, игровом или пародийном употреблении советизмов см. НАм 2014а.

${ }^{2}$ http://www.gramota.ru/biblio/magazines/gramota/opinia/28_54. 
законодательные акты, и публичный дискурс (popular discourse), содержание которого составляют научные дискуссии о языке и дискуссии в масс-медиа (RyAZANOVA-ClaRKe 2006: 33).

\section{2. Пуризм в советской языковой политике ${ }^{3}$}

В истории русского языка пуризм характеризуется, в основном, критическим отношением к заимствованиям. В XVIII и XIX веках писатели А. П. Сумароков и Н. И. Новиков выступали против засорения русского языка французскими терминами. М. В. Ломоносов в своей «Теории трех штилей» не оставил места для заимствований из неславянских языков, предложив заменить слова театр и иирк на зрелище и позорище. А. С. Шишков в «Рассуждении о старом и новом слоге российского языка» (1803) отвергал лексические, семантические и синтаксические новшества, опираясь на славяно-русскую архаику, отстаивал принцип неизменности литературного языка. ${ }^{4}$ Однако в целом до начала XX века в обсуждении о языке в российском обществе пуризм занимал лишь периферийную позицию.

Строгая нормализация началась после Октябрьской революции, когда так называемый язык улицы начал оказывать мощное влияние на язык прессы, художественных произведений. Изменилась социальная структура общества, интеллигенция утратила ведущую роль в культурном развитии, крестьянство и рабочие классы стали передовой частью общества и, соответственно, произошел массовый приток просторечных и диалектных единиц в литературный язык. Данный процесс вызвал тревогу и стимулировал движение в защиту языка в 1920-х годах. Концепция «чистоты языка» была актуализирована сначала в речи ученых и литераторов. Началось формирование новой научной дисциплины «культура речи», основателем которой является Г. О. Винокур. ${ }^{5}$

${ }^{3}$ Подробнее о пуризме в советской языковой политике см. НАм 2015.

${ }^{4}$ В противоположность этому, Н. М. Карамзин в духе европейской традиции «пишут, как говорят» настаивал на сближении книжного и разговорного языка, подчеркивал необходимость заимствований и упрощения синтаксиса. Споры между Шишковым и Карамзиным известны как противостояние между славянофилами и западниками относительно модели развития русского литературного языка. Однако В. М. Живов указывает, что и Шишков, и Карамзин оба были заинтересованы в чистоте языка, только с разных точек зрения (Живов 1996: 155-264, 419-456). Согласно Б. А. Успенскому, обе стороны установили свои рамки аргументации в терминологии «свой» и «чужой» (УСПЕнский 1994: 167, цит. по GORHAM 2006: 20).

${ }^{5}$ Термин «культура языка» или «культура речи» (language culture) в позднесоветское время употреблялся главным образом в дидактическом смысле, однако в последнее время он стал стержневым концептом пуристического дискурса о языке (GORHAM 2001: 6). Х. Шиффман тоже предлагает термин «культура языка», но немного в другом смысле. Рассматривая языковую политику в культурном контексте, он полагает, что языковая культура - это совокупность норм поведения, убеждений, культурных форм, фольклорных убеждений, отношения к языку, стереотипов, образа мышления о языке, и, наконец, религиозно-исторического окружения, ассоциируемого с определенным языком (SCHIFFMAN 1996: 5). 
Однако сигналом для начала широкого обсуждения данной проблематики стала публикация в газете «Правда» заметки В. И. Ленина «Об очистке русского языка» (Правда 1924, №275, 1). Именно после появления этой заметки в печати, чистота языка стала одной из идеологем власти, и в газетах начали обращаться к вопросам языкового строительства, выступая против жаргонизации речи и неумеренного словотворчества современных литераторов.

Как показывает дальнейшая история русского языка, советские вожди прекрасно осознавали, что советская империя могла бы удержаться лишь при централизованной власти государства, что означает тоталитаризм во всех сферах жизни, в том числе, в языке, так как язык оказывает значительное влияние на процессы социализации личности, с его помощью осуществляется манипулирование общественным сознанием. А для формирования четко выработанного, единого языка, отторгающего любые стихийные новообразования и инакомыслие, нужна была широкомасштабная пропаганда с мифологемами, способными направлять массу против реальных или вымышленных противников. Именно концепция «чистоты языка» соответствовала таким задачам. Итак, после победы коммунистической партии был сформирован институт цензуры и введена монополия на идеологию и пропаганду.

Что интересно, в советское время общественная пропаганда за чистоту языка проводилась главным образом посредством прессы, так как именно она служила важным инструментом поддержания государственного строя. В прессе регулярно публиковались материалы о величии русского языка и о грозящих ему опасностях и необходимости его защиты.

В 1930-х годах борьба за чистоту языка в прессе приобретает все более политический, пропагандистский характер. В «Литературной газете» подчеркивалось, что «борьба за чистоту языка имеет не только стилистическое, но и политическое значение. Произвольное словоупотребление, игнорирование синтаксиса способствуют контрабандному протаскиванию всякого вздора и обусловливают разнузданность мышления» (Литературная газета 1934, №16, 1). Далее разъяснялось, что при социализме стихийное развитие языка невозможно, языковое строительство ведется сознательно и планомерно, являясь частью воспитания масс (Литературная газета 1934, №48, 50, 52, 56). В политизации борьбы за чистоту языка не отставала от «Литературной газеты» и «Правда». В статье «О чистоте языка наших газет» в «Правде» (1934 г.) был поставлен знак равенства между культурой речи и политикой: «Борьба за чистоту языка наших газет есть... борьба за чистоту путей пролетарской революции, за устранение всяких преград между словами революции и массами...» (Правда 1934, №325, 1).

В список врагов языка были включены не только средства усложнения стиля (словесные украшения, риторическая избыточность), но и приемы стилизации под живую народную речь (просторечные и диалектные слова и конструкции). Таким образом, в первый революционный период языковая политика была направлена на очищение языка от таких необщенародных единиц, как вульгаризмы и провинциализмы, которые якобы воплощали неразвитое 
крестьянское сознание. Данное решение Е. Н. Басовская объясняет некоторой ложной революционностью в языковой политике советской власти. Следовательно, несмотря на словесное прославление революции и трудового народа, официальная пропаганда проявляла настороженность в отношении истинно народного и революционного, отрицая народную речевую стихию (БАСОВСКАЯ 2011).

Затем, после Великой Отечественной войны, начиная с середины 1940-х годов, ожесточилась борьба власти против инакомыслия. В это время борьба за чистоту языка практически представляла собой борьбу против чуждых, вредных явлений и слово «пуризм» служило для дискредитации инакомыслящих оппонентов. В частности, в связи с советским изоляционизмом резко осуждалось употребление заимствованных слов. Иноязычные слова ассоциировались с чем-то идеологически чуждым, враждебным, и уже вошедшие в обиход заимствования переименовывались. Например, грейдер $\rightarrow$ cтруг, бульдозер $\rightarrow$ тракторный отвал (НАм 2013: 122). Осуждение заимствованных слов имело мотив формирования у народа неприязненного отношения ко всему внешнему, в частности, западному. Поэтому во многих газетных публикациях по языковой теме употребление иностранной терминологии рассматривалось как политическая ошибка. ${ }^{6}$

Таким образом, со временем борьба за чистоту языка перешла в борьбу за унификацию речи, за идеологически выверенный советизированный язык, а именно новояз. ${ }^{7}$ В подобной стандартизации языка был скрыт идеологический подтекст, направленный на стилистическое обезличивание и единообразие мысли. Итак, произошла отчетливая политизация дискуссии о языке, которая делала акцент более на соответствии современного русского языка великим задачам построения социализма, нежели на качестве его употребления.

Однако в условиях оттепели, хотя власть и продолжала эксплуатировать лозунг борьбы за чистоту языка, в научных и публицистических кругах проводился более профессиональный, менее идеологически настроенный анализ языковых явлений. Лингвисты стали уделять больше внимания опасности излишне гладкого, безликого языка с многочисленными клише, и, тем самым, определенно отмежевались от предшествующего периода.

\footnotetext{
${ }^{6}$ Например, материал Б. Агапова и К. Зелинского «Нет, это - не русский язык!» (Литературная газета 1947 , №59, 3).

${ }^{7}$ Как известно, термин «новояз» (newspeak) получил распространение после перевода на русский язык знаменитой антиутопии Оруэлла «1984 год». В этом произведении описан язык, специально разработанный для манипуляции общественным мнением (сознанием), призванный направить мыслительные процессы людей в требуемое манипуляторам русло. «Новояз» как термин обозначает тоталитарный язык, т. е. язык общества, в котором все сферы социальной и духовной жизни подвергаются идеологизации. В частности, в публицистике этим термином нередко обозначаются языки официальных документов и периодики нацистской Германии и СССР. Аналогичное название есть и в других славянских языках, ср., например, польск. nowomowa. О спецификах новояза и его рефлексии в современном русском языке см. HAM 2014b.
} 
О новой тенденции в языковой дискуссии в это время свидетельствует и рубрика «Служба русского языка», появившаяся в 1964 году в «Литературной газете». Эксперты «Службы русского языка», в том числе К. И. Чуковский и Л. В. Успенский, поставили перед собой задачу отказа от пропагандистских лозунгов и перехода к реальному лингвистическому просвещению читателей. При оценке речевых фактов представители «Службы русского языка» руководствовались функциональным принципом, предлагая новаторскую мысль о бесперспективности сознательного, искусственного очищения языка. Исходя из этого, они настаивали на необходимости изменения литературных норм в соответствии с узусом, в частности - в отношении семантических изменений и широкого употребления новых заимствований. Тем самым, деятельность «Службы русского языка» шла вразрез с духом советского пуризма, в рамках которого утверждалась неизменяемость норм литературного языка в независимости от узуса, и наоборот, подчеркивалась необходимость вмешиваться в реальное употребление языка.

Далее, в позднесоветский период, в условиях идеологической стагнации советского общества борьба за чистоту языка постепенно утрачивала актуальность.

Как мы упомянули выше, борьба за чистоту языка представляет собой основную часть языковой политики советской власти. Подчеркнутое внимание руководства советской власти к языку связано с пониманием ключевой роли языка в формировании мировоззрения у его носителей. Л. И. Скворцов указывает то, что в основе взглядов советских языковедов лежит признание возможности регулировать социальную речевую деятельность, решать теоретические и практические вопросы культуры речи и языковой политики (Скворцов 1969: 51). К результатам такого подхода можно отнести появление в советское время многочисленных словарей, в том числе и орфографических, учебных пособий, создание кафедр русского языка в ряде вузов и т. д.

Важно, как нам кажется, также то, что пуристическая окраска наблюдается и в дискурсе о языке в постсоветский период. Об этом речь пойдет ниже.

\section{3. Пуризм в постсоветской языковой политике}

Дж. Данн указывает на десоветизацию и вестернизацию как на главные тенденции современного русского языка (ДАнн 2009). Десоветизация - это устранение языковых черт, появившихся под влиянием советской системы, и так или иначе связанных с ней. А под вестернизацией подразумевается внедрение языковых черт, присущих английскому и европейским языкам.

По мере того, как усиливались эти тенденции, общественность начала обращать внимание на состояние языка. На эту тему писали и говорили журналисты, политики, писатели, ученые, да и просто рядовые носители языка. В средствах массовой информации и в специальной литературе последнего десятилетия часто обсуждались следующие языковые вопросы: «сохранение 
русского языка», «порча и гибель русского языка», «засилье иностранных слов», «сквернословие в публичной речи», «речевая культура депутатов», «грамотность населения», «реформа орфографии», «закон о государственном языке», «изучение русского языка в средней школе», «русский язык за рубежом» и т. д. (Химик 2008: 13).

В целом в дискуссии о состоянии современного русского языка, и о том, каким он должен быть, наблюдаются два противоположных мнения, каждое из которых с некоторым упрощением можно назвать либеральным и пуристическим (GoRHAм 2006: 20). ${ }^{8}$ Либералы, свободные от существующих догм и авторитетных подходов к языку, убеждают в необходимости демократизации общественного строя, социальной системы, что подразумевает под собой и предоставление массе широкого, открытого канала публичной коммуникации. В подобную массовую коммуникацию непременно входят альтернативные единицы, в частности, диалектизмы, провинциализмы, грубые слова и заимствования.

Голоса же пуристов в первое время не привлекали внимание общественности. Их выступления ограничивались, главным образом, непопулярными брошюрами, такими как «Культура парламентской речи», энтузиастскими лозунгами типа «Мы сохраним тебя, русская речь» или псевдонаучными конференциями по теме защиты русского языка или о судьбах русского православия.

Выступления пуристов стали носить массовый характер в середине 90-х годов, когда в России усугубились социальный, политический и экономический кризисы. Затяжной и тяжелый переход к рыночной экономике и разрушение иллюзий о западной демократии привели многих россиян к отчаянию и поиску «исконно своего, потерянного». И вот, на фоне усиления ощущения, что Россия будто бы потеряла свою дорогу, начались активные дискуссии о формировании новой национальной идеи, а язык как всегда является фундаментом формирования национальной идентичности. ${ }^{9}$ В рамках этого в 1995 году указом президента РФ №1221 был учрежден Совет по русскому языку при президенте, куда вошли видные писатели, филологи и высокопоставленные государственные чиновники. Им было поручено делать отчет президенту о важных вопросах по развитию русского языка. ${ }^{10}$

\footnotetext{
${ }^{8}$ Такое противопоставление во взглядах на языковые процессы напоминает историческое противостояние между славянофилами и западниками или, как их еще называют, архаистами и новаторами. Ю. Н. Тынянов в своей работе выявляет ряд фундаментальных качеств, присущих историческим дискуссиям о языке между архаистами и новаторами. Одно из них стремление переместиться на общественно-политическую почву, что также характерно для обсуждения проблемы «чистоты языка» (Тынянов 1929).

${ }^{9}$ О соотношении между языком и национальностью, русскостью (Russianness) см., в том числе, БЕЛИКОВ 2005, АРАПОВ 2006, ХимИк 2008.

${ }^{10}$ В 1997 году Совет по русскому языку при президенте РФ был преобразован в Совет по русскому языку при Правительстве РФ. Потом в 2014 году указом Президента РФ №409 был снова образован Совет при Президенте по русскому языку.
} 
C началом XXI века состояние русского языка еще более привлекает к себе массовое внимание общественности. По этому поводу Л. РязановаКларк замечает, что в метадискурсе о современном русском языке подчеркиваются метафоры угрозы и болезни (см. RYAZANOVA-CLARKE 2006: 34-41). Следовательно, в дискуссиях о состоянии русского языка все чаще выходит на первый план та позиция, согласно которой русский язык подвергается атакам извне и изнутри. В качестве примера приводятся различные опасения по поводу состояния русского языка, звучащие в российских СМИ. Например, в газете «Аргументы и факты» была опубликована статья под заглавием «Язык с хреном. Новая лексика проникает в русский язык через несколько лазеек», в которой говорится, что над русским языком нависли угрозы посерьезнее, и правительство должно спасать русский язык законами. ${ }^{11}$

В академических кругах президент Международной ассоциации преподавателей русского языка и литературы Л. А. Вербицкая, известная как один из самых последовательных сторонников борьбы за чистоту русского языка, отмечает: «Постепенно в литературный язык проникают просторечные пласты. Язык - это форма существования сознания. И преобладание примитивного, грубого, агрессивного языка говорит о соответствующем сознании нации... Степень раскованности современной русской речи дошла до предела». ${ }^{12}$

Вслед за ней, многие ученые также ставят негативный диагноз относительно состояния русского языка, мол, в последние годы разговорной нормой становится ненормативная лексика, русский язык «болен». ${ }^{13}$ Зачастую высказываются опасения, что в современном русском языке разрушаются форма и содержание великого русского языка - языка Пушкина, Блока, Достоевского и Толстого (ГрАудинА и др. 1995). Далее цитируем высказывания лингвистов, которые тревожатся относительно «болезненного» состояния русского языка: «Сегодня мы наблюдаем процесс его [русского языка - Н. Х. Х.] сознательной деформации и искажения. ....на русский язык оказывают давление две силы... Первое направление воздействия на язык - снизу, от простых людей, которые особо не заботятся о правильности речи, которые считают,

\footnotetext{
${ }^{11} \mathrm{Cp} .:$ «наш с вами „великий и могучий“ стремительно становится все труднее для понимания. Филологи бьются в конвульсиях. Ежедневно в русский язык вливается по 7 иностранных варваризмов образца: портфолио и топлес. Казалось бы, ну и что? А то! Если активно заимствующая лексика в языке превышает 2-3\%, лингвисты уверенно прогнозируют очень скорое ИСЧЕЗНОВЕНИЕ язЫка. А у нас количество всех этих „ТАМПАКСОВ“ перевалило за 10\%!» (Аргументы и факты 2004, №5).

${ }^{12} \mathrm{http}: / /$ paperpaper.ru/lector-verbizkaya.

${ }^{13} \mathrm{~B}$ последнее время появился ряд как коллективных, так и индивидуальных работ, описывающих языковые изменения, происходившие в конце XX и начале XXI веков (ЗЕмСКАЯ 1996, КРысин 2008, КРысин 2010, КАРАУЛОв 2001, Химик 2006 и др.). Авторы данных работ исследуют новые тенденции в лексике, семантике, словообразовании и грамматике, а также в стилистических характеристиках слов и в соотношении функциональных стилей и речевых жанров. Однако при оценке таких изменений лингвисты часто выражают тревогу, опасение относительно «болезненного» состояния русского языка.
}

Studia Slavica Hung. 60, 2015 
что сленг делает их речь современной. [...] Второе направление - сверху, от начальников, чиновников, руководителей... они озабочены идеологией, воздействием на сознание людей. С этой целью они манипулируют словами, применяя их искусственную десемантизацию» (СЕРЕБРянСКАЯ 2014: 180-181); «Русский язык великий, могучий, но беззащитный» (ГАРАБАЕВ 2007: 24). Таким образом, создается представление о болезненном, загрязненном состоянии русского языка.

Для тех, кто придерживается пуристического взгляда, существует некий абсолютный, идеальный язык, а говорящие виноваты в загрязнении языка путем неправильного его употребления. И при этом, по их мнению, самую большую опасность и угрозу для русского языка представляют различные субстандарные единицы: просторечные, вульгаризмы, уголовная лексика и профессиональные арго, сленг. В частности, заимствования из западноевропейских языков, прежде всего, из английского, воспринимаются как самые агрессивные единицы, нарушающие чистоту и норму русского языка.

Процессу принятия новых массовых заимствований способствовали не только открытая ориентация на Запад в различных областях общества, но и отсутствие их эквивалентных слов в русском языке, возможность сократить многословные описательные обороты посредством заимствований, их терминологические свойства и, наконец, восприятие иноязычного слова как более престижного, «лучше звучащего» (JANURIK 2010: 46-48), сp. mepмonom термос и чайник в одном бытовом приборе; презентачия - представление; эксклюзивный - исключительный.

Как правило, эти иноязычные слова вначале использовались в узкой профессиональной сфере, но по мере того, как явления, обозначаемые этими терминами, становились остроактуальными для всего общества, узкоспециальная терминология начинала употребляться в СМИ и затем проникала в речь рядовых носителей языка.

Однако, вопреки массовому употреблению заимствований, в отношении к ним преобладают отрицательные оценки. С конца XX века все более распространялось мнение, устойчиво соотносящее язык с национальной идентичностью. Убеждая общество в том, что язык служит живым выразителем народного миросозерцания, и в то же время оказывает значительное влияние на мысль, сторонники пуризма противопоставляют исконно русские слова и заимствования не только как правильное/неправильное употребление языка, но и как моральное/аморальное, чистое/грязное, свое/чужое, духовное/материальное. Например, Л. Савельева пишет, что русское «любовь» имеет высокую этическую ценность, и в то же время английское «секс», обозначая лишь физическую увлеченность, искажает мировоззрение русского народа. Далее из этого она делает следующий вывод: «Злоупотребление модными англо-американизмами - это искусственное внедрение чужеродных элементов в самобытное мировидение этноса. Это влечет за собой утрату этнических ориентиров русской культуры, а значит, вносит свой вклад в разрушение нравственного здоровья нашего общества» (САВЕльЕВА 2000: 59-61). 
Таким образом, устанавливается прямое соотношение между чистотой языка и чистотой самой жизни. В. В. Щеулин пишет: «На основе снижения общей культуры населения, падения нравственности стало обычным массовое сквернословие в бытовом, общественном и официальном общении. [...] Лишь только „черное слово“ становится в ряд с остальными словами нашей речи как равноправное, возникает, даже помимо сознания, словесная неразборчивость, а вслед за ней - неизбежная склонность к нравственному безразличию и смешению добра и зла» (ЩЕулин 2008: 251).

Также и СМИ стали активнее говорить о величии русского языка и в то же время о его болезненном состоянии и угрозах, нависших над ним. Например, в ряде газет появились специальные рубрики типа «Поговорим о языке», «Наш язык», «Русская речь», «Давайте говорить правильно». Передачи о русском языке завели также многие крупные радиостанции: радио «Маяк» (Грамотей), «Радио Россия» (С русского на русский, или Как сказать), «Эхо Москвы» (Говорим по-русски, Как правильно). В журнале «Знамя» действовала специальная рубрика «Родная речь», где публиковались дискуссионные очерки ученых.

Естественный вывод из таких опасений - создание мер с целью защиты и сохранения русского языка от внешней и внутренней атак, что реализуется на государственном уровне. Итак, предлагается ряд программ и законопроектов, нацеленных на защиту чистоты языка. Например, в 2000 году в правительстве РФ был создан Совет по сохранению чистоты русского языка. Основными задачами Совета являются: сбор, анализ, обобщение и доведение до сведения правительства РФ информации о проблемах развития, распространения и сохранения чистоты русского языка; подготовка для правительства рекомендаций по разрешению данных проблем. В 2005 году В. Путин утвердил «Закон о государственном языке РФ», который придает русскому языку статус официального государственного языка и направлен на защиту и развитие языковой культуры.

Также дан старт федеральным целевым программам «Русский язык 2001-2005», «Русский язык 2006-2010», бюджет которых за прошедшее десятилетие существенно увеличился. Там указано, что нормы литературного языка не соблюдаются, слова паразиты, неоправданные иноязычные заимствования все чаще встречаются в речи ведущих телепередач и радиопередач. ${ }^{14}$ Эти целевые программы направлены на обновление мер языковой политики, поддержку исследований по русскому языку, спонсирование телепередач и радиопередач, пропагандирующих чистоту русского языка и его правильное употребление и, в конечном счете, на повышение уровня языковой культуры.

Помимо этого, в Интернете стали действовать специальные языковые порталы (gramota.ru, gramma.ru, ropryal.ru и т. д.), созданы Национальный

\footnotetext{
${ }^{14}$ Фрагмент документа «О федеральной целевой программе „Русский язык на 2002-2005 годы“» (редакция на 25.11.2003). http://elementy.ru/Library9/Progr483.htm. 
корпус русского языка (http://www.ruscorpora.ru) и Национальный корпус русского литературного языка (http://www.narusco.ru), похожие на английский COBUILD, и также активно предлагаются к использованию обширные сетевые собрания словарей русского языка (http://www.rubricon.com, http:// www.slovari.ru, http://www.lsw.ru и др.).

Однако, пожалуй, апофеозом внимания к русскому языку стал Год русского языка. 2007 год в России был объявлен Годом русского языка. В рамках Года русского языка было проведено около 100 общенациональных и международных форумов, конференций, семинаров и круглых столов русистов, более 60 фестивалей, Дней и Недель русского языка, русской книги, российской культуры и образования и 30 олимпиад, конкурсов, викторин по русскому языку. На пресс-конференции, посвященной итогам Года русского языка, крупный политолог В. Никонов напомнил, что основными целями Года русского языка является не только повышение интереса к изучению русского языка, литературы и культуры, но и укрепление позитивного имиджа России как внутри страны, так и в мировом сообществе. ${ }^{15}$

Именно в 2007 году в целях систематичного продвижения русского языка был создан фонд «Русский мир». Учредителями выступают Министерство образования и науки и Министерство иностранных дел. Фонд «Русский мир» рассматривает языковые вопросы в более широком аспекте, соотнося его с концепцией «русский мир». Зачины идеи «русского мира» можно найти в средние века, например, в концепции Третьего Рима, разработанной иноком Филофеем. Однако в конце XX века к этой идее снова возвращались как к сумме всего потерянного из-за крушения советской империи, прозападной политики, моральной и политической катастрофы (см. ГЕФтЕР 1995, ПАВЛОВСКИЙ-ЧЕРНЫШЕВ 1997). ${ }^{16}$

В современном политическом русле концепция «русский мир» была разработана Петром Щедровицким (см. ЩЕдровицкий 2000) и затем еще дополнена и апробирована политологами, близкими к Кремлю (см. Тишков 2007). По их мнению, «русский мир» является сетевой структурой сообществ, говорящих и мыслящих по-русски, и принадлежность к русскому миру определяется именно знанием русского языка, культуры и вниманием к России. Следовательно, русский язык считается эффективным средством для формирования идентичности «русского мира». Это получило отражение в политике РФ, которая нуждалась в едином, всеобъемлющем подходе к проблемам диаспоры и русскоязычного контингента. ${ }^{17}$

${ }^{15} \mathrm{http}: / /$ pedsovet.org/content/view/3887/265. 2012

${ }^{16}$ Об истории понятия «русский мир», его современном развитии и воплощении см. NAM

${ }^{17}$ В 2001 году на Конгрессе соотечественников, проживающих за рубежом, президент РФ В. В. Путин сказал следующее: «Понятие „русский мир“ испокон века выходило далеко за географические границы России и даже далеко за границы русского этноса. [...] Но я абсолютно уверен в том, что какие бы проблемы перед нами не стояли, ничто не помешает нам чувствовать и стать по-настоящему единым народом». 
Следовательно, в круг деятельности и задач фонда «Русский мир» входят не только сохранение чистоты русского языка, повышение языковой культуры, но и поддержка организаций, занимающихся проблематикой, связанной с «русским миром», формирование благоприятного для России общественного мнения, взаимодействие с диаспорами и др. ${ }^{18}$ Такой многопрофильный характер деятельности фонда подтверждает специфику постсоветской языковой политики, акцентирующую связь чистоты языка с ее национальной идентичностью и морально-этической стороной жизни.

\section{4. Выводы}

Как мы уже отмечали ранее, в советское и в постсоветское время чистота языка была составной частью дискурса о языке как на публичном, так и на официальном, т. е. государственном уровне. В рассматриваемые два периода в список врагов языка включены просторечные, диалектные слова, конструкции и всякие новообразования, в том числе, заимствования. Эти враждебные единицы языка воспринимаются как периферийные, которые нужно изгонять из употребления. Именно на очищение языка от таких необщенародных единиц была направлена языковая политика и нормализация. В частности, негативные отношения к диалектам показывают ложность провозглашенных высказываний о том, что диалекты якобы обогащают язык. ${ }^{19}$ При этом в оба рассматриваемых периода пресса сыграла и играет важнейшую роль в формировании и распространении пуристического дискурса о языке.

В эти два описываемые периода в пуристически настроенном дискурсе о языке часто проявлялось стремление улучшить язык искусственным образом, т. е. стремление к культивации языка (language cultivation). Обычно под языковой культивацией подразумевается нормализация и защита стандартного, литературного языка. На публичном уровне языковая культивация реализовалась в призывах ученых и публицистов, основанных на дихотомическом подходе к языку, изгонять из языка «плохие» единицы, как, например, орфоэпические, орфографические вариации, социальные и территориальные диалекты. На государственном же уровне предлагались программы и законопроекты, нацеленные на защиту чистоты языка, в частности, упразднение «неблагопристойных» единиц языка.

Вследствие пуристического подхода к языку сложилось официальное представление о языковом идеале, и о том, что ему не соответствует. В советское время хорошим, идеальным был признан простой, ясный, доступный и также благопристойный язык. Образцовой моделью служил язык партийных

\footnotetext{
${ }^{18} \mathrm{O}$ целях и задачах фонда «Русский мир» см. http://www.russkiymir.ru/fund/.

${ }^{19}$ Например, о достоинстве диалектизмов Ю. Н. Караулов пишет: «диалекты составляют мощный коммуникативный ресурс языка. Далее, важным показателем для реализации энергетического коммуникативного потенциала языка является его использование во всех видах речевой деятельности» (http://www.gramota.ru/biblio/magazines/gramota/russianworld/28_106). 
руководителей. В постсоветское же время для сторонников пуризма образцовой моделью языка служит язык «великого» прошлого.

А на что способна официальная политика? Что она может изменить? Обычно возможности и воздействие официальной языковой политики гораздо скромнее, чем существующие на этот счет в обществе ожидания. Традиционно для России была характерна существенная переоценка нормализаторских возможностей по отношению к языку. В своей монографии «Тhе Russian Language in the Twentieth Century» Б. Комри пишет, что в России культура языка, языковое нормирование и языковая кодификация воспринимались как синонимы языкового планирования (COMRIE-STONE-POLINSKY 1996: 6). Советская языковая политика хотя и создала новый политически выверенный язык - новояз, но не могла внести существенных изменений в употребление языка на бытовом уровне. Об этом свидетельствует «двуязычие» или «диглоссия» в советское время. Как полагается, в советское время в газетах и на партсобраниях царил новояз, а в бытовой сфере - разговорная, литературная или просторечная речь в зависимости от речевой ситуации и ее участников. По этому поводу М. А. Кронгауз пишет, что в советском обществе сосуществовали два языка: русский язык и советский русский языкновояз. Советский русский язык в основном использовался в советском ритуальном общении (КРОНГАуз 2002).

Однако в то же время нельзя недооценивать смысл языковой политики, в частности, концепции «хорошая речь», к чему стремится вся политика по повышению языковой культуры. Под данной концепцией подразумевается, что язык правильно употребляют лишь немногие говорящие, в большинстве случаев - представители элитной культуры. Только их язык признается образцовым, надлежащим, а единицы из языков остальных групп считаются ошибками. При таком подходе отвергаются любые инновации, изменения и вариативность языка. Тем самым, концепция «хорошая речь» или «чистота языка», базируясь на иерархической языковой культуре и социальной стратификации, отвергает широко распространенный тезис об имманентной языковой компетенции говорящего употреблять различные стилистические единицы в зависимости от контекста.

\section{Литература}

АРАПОВ 2006 = АРАПОВ М. Наш великий и могучий... Знамя 2006/2. http://magazines. russ.ru/znamia/2006/2/ara10.html.

БАСОВСКАЯ 2011 = БАСОВСКАЯ Е. Н. Кониепт «чистота языка» в советской газетной пропаганде. АДД. Москва. 2011.

БЕликОВ 2005 = БЕликОВ В. И. Национальная идея и культура речи. Отечественные записки 2005/2. http://magazines.russ.ru/oz/2005/2/2005_2_4.html.

ГАРАБАЕВ $2007=$ ГАРАБАЕВ Б. В защиту русского язЫка. Обозреватель 2007/3: 22-28.

ГЕФТЕР 1995 = ГЕФтЕР М. Мир миров: российский зачин. Русский архипелаг 1995. http://www.archipelag.ru/ru_mir/history/history95-97/gefter-zachin. 
ГРАУДИНА 1995 = ГРАУДИНА Л. К. Мы сохраним тебя, русская речь! Москва, 1995.

ДАнн 2009 = ДАнн Дж. А. Трансформация русского языка из языка советского типа в язык западного образца. В кн.: БудАЕВ Э. В., Чудинов А. П. Лингвистическая советология. Екатеринбург, 2009. 258-274.

Живов 1996 = Живов В. М. Язык и культура в России ХІІІ века. Москва, 1996.

ЗЕМСКАЯ 1996 = ЗЕМСКАЯ Е. А. (ред.) Русский язык конйа ХХ столетия (1985-1995). Москва, 1996.

КАРАУЛОВ 2001 = КАРАУЛОВ Ю. Н. О состояНИИ современНОГо русского языка. Русская речь 2001/3: 25-30.

КРОНГАУз 2002 = КРОНГАУз М. А. ЯзЫК мой - враг мой? Новый мир 2002/10: 135-141.

Крысин 2008 = Крысин Л. П. (ред.) Современный русский язык. Активные процессы на рубеже XX и XXI веков. Москва. 2008.

Крысин 2010 = Крысин Л. П. (ред.) Современный русский язык: система - норма узус. Москва, 2010

НАм 2013 = НАм Хе Хен: Некоторые размышления о заимствованиях в современном русском языке в плане нормы и нормализации. European Society and Culture 2013/10: 113-142.

НАм 2014a = НАм Хе Хен: К исследованию советскости в современном русском дискурсе и языковой политике в постсоветском пространстве. Slavic Almanach 20 (2014): 86-102.

НАм 2014b = НАм Хе Хен: Рефлексы новояза в современном русском языке. Studia Slavica Hung. 59 (2014): 377-392.

НАм 2015 = НАм Хе Хен: Языковой пуризм и его социальный смысл: на примере языковой политики СССР. In: Far East, Near Russia. Evolution of Russian Culture from Eurasian Perspective. Saitama, 2015. [В печати.]

ПАВЛОВСКИЙ-ЧЕРНЫШЕВ 1997 = ПАВЛОВСКИЙ Г., ЧЕРНЫШЕВ С. К возобновлению русского. Русский журнал 1997. http://old.russ.ru/journal/dsp/97-07-14/pav-che.htm.

САВЕЛЬЕВА 2000 = САВЕЛЬЕВА Л. В. РУсское слово: конец ХХ века. Санкт-Петербург, 2000.

СЕРЕБРЯНСКАЯ 2014 = СЕРЕБРЯНСКАЯ Н. А. Я Перестала ПоНИМать родной русский язык. Экология языка и коммуникативная практика 2014/1: 174-181.

СквоРцОв 1969 = СквоРцОв Л. И. Основы нормализации русского языка. Русская речь 1969/4: 42-51.

Тишков 2007 = Тишков В. А. Русский мир: смысл и стратегия. Стратегия России 2007/7. http://sr.fondedin.ru/new/fullnews_arch_to.php?subaction=showfull\&id=1177 $590461 \&$ archive $=1177590905 \&$ start_from $=\& u c a t=14 \&$.

Тынянов 1929 = Тынянов Ю. Н. Архаисты и новаторы. Ленинград,1929.

УСПЕНСКИЙ 1994 = УСПЕНСКИЙ Б. А. Краткие очерки истории русского литературного языка (XI-XIX вв.). Москва, 1994.

Химик 2006 = Химик В. В. Болезнь языка или язык болезни. В кн.: БогдАнов С. И., Рогожина Н. О., Юрков Е. Е. Современная русская речь: состояние и функичионирование. Вып. 2. Сборник аналитических материалов. Санкт-Петербург, 2006. $148-150$.

Химик 2008 = Химик В. В. Национальная идея и русский язык. Политическая лингвистика 2008/3: 9-16.

ЩЕДРОВИЦКИЙ 2000 = ЩЕДРОВИЦкИй П. Русский мир и Транснациональное русское. Русский журнал 2000. http://old.russ.ru/politics/meta/20000302_schedr.html. 
ЩЕулин 2008 = ЩЕУлин В. В. Реализация государственной политики по поддержанию статуса русского языка как государственного языка России. Филоlogos 2008/ 1-2: 247-254.

Comrie-Stone-Polinsky 1996 = Comrie B., Stone G., Polinsky M. The Russian Language in the Twentieth Century. Oxford, 1996.

Gorham 2000 = Gorham M. S. Natsiia ili snikerizatsiia? Identity and Perversion in the Language Debates of Late- and Post-Soviet Russia. The Russian Review 59 (2000): 614-629.

Gorham 2006 = Gorham M. S. Language Culture and National Identity in Post-Soviet Russia. In: Lunde I., RoESEN T. (eds.) Landslide of the Norm. Language Culture in Post-Soviet Russia. (Slavica Bergensia 6.) Bergen, 2006. 18-30.

JANURIK $2010=$ JANURIK Sz. The Integration of English Loanwords in Russian: An Overview of Recent Borrowings. Studia Slavica Hung. 55 (2010): 45-65.

NAm 2012 = NAm H. H. Rusofonija, runet in ruski jezik. Slavistična revija 60 (2012): 165183.

RyAZANOVA-Clarke 2006 = RYAZANOVA-Clarke L. The Crystallization of Structures. Linguistic Culture in Putin's Russia. In: Lunde I., ROESEN T. (eds.) Landslide of the Norm. Language Culture in Post-Soviet Russia. (Slavica Bergensia 6.) Bergen, 2006. 31-63.

SCHIFFMAN 1996 = SCHIFFMAN H. Linguistic Culture and Language Policy. London, 1996. 